1996

\title{
Media use and voter turnout in a presidential election
}

James L. Simon

Fairfield University, jsimon@fairfield.edu

Follow this and additional works at: https://digitalcommons.fairfield.edu/english-facultypubs

Copyright 1996 Newspaper Research Journal

Archived with permission from the copyright holder.

\section{Peer Reviewed}

\section{Repository Citation}

Simon, James L., "Media use and voter turnout in a presidential election" (1996). English Faculty

Publications. 49.

https://digitalcommons.fairfield.edu/english-facultypubs/49

\section{Published Citation}

Simon, James (1996). "Media use and voter turnout in a presidential election." Newspaper Research Journal, 17(1-2), 25-34.

This item has been accepted for inclusion in DigitalCommons@Fairfield by an authorized administrator of DigitalCommons@Fairfield. It is brought to you by DigitalCommons@Fairfield with permission from the rightsholder(s) and is protected by copyright and/or related rights. You are free to use this item in any way that is permitted by the copyright and related rights legislation that applies to your use. For other uses, you need to obtain permission from the rights-holder(s) directly, unless additional rights are indicated by a Creative Commons license in the record and/or on the work itself. For more information, please contact digitalcommons@fairfield.edu. 


\section{Media use and voter turnout in a presidential election}

by James Simon

This study suggests that newspaper use is related to likelihood that a person will vote. The use of television, radio and magazines, on the other hand, is not linked to voting.

$\mathbf{T}_{\mathrm{t}}$ he relationship between news media use and voting behavior has interested researchers since the 1940 s, when Paul Lazarsfeld's pioneering effort found that the news media in the pretelevision era helped activate citizens and boosted turnout. ${ }^{1}$ Despite Joseph Klapper's 1960 conclusion about the limited effects of the mass media, ${ }^{2}$ more recent work has detailed the role of the news media as a major information source in election campaigns and has found individual mediums to be associated with specific effects on audiences.

For example, newspaper users tend to obtain and retain more information on political campaigns, ${ }^{3}$ are able

Traditional news sources like the New York Times, news magazines and network newscasts found themselves competing for stories and audiences with these alternative sources, which ranged from $M T V$ and the Nashville Network to talk shows hosted by Larry King on television and Rush Limbaugh on radio.

to discriminate among issues ${ }^{4}$ and use the medium to reinforce political attitudes. ${ }^{5}$ Public understanding of campaign issues is even greater when a city has two competitive daily newspapers. ${ }^{6}$ In contrast, television users are less active politically, ${ }^{7}$ less likely to hold political views ${ }^{8}$ and more likely to use candidate images and personal qualities in making a voting choice. ${ }^{9}$

Simon is an assistant professor in the department of communication at the University of the Pacific in Stockton, California. This study is adapted from the author's doctoral dissertation. The author would like to thank Nicholas Alozie, Bruce D. Merrill, David Sachsman and Kenneth Day for their helpful comments. 
Far less work has been done on the question of whether a citizen's reliance on a particular news medium for election campaign information is significantly related to whether they voted in that election. The 1992 presidential campaign presented an unusual opportunity for such a study. Campaign information continued to be available from traditional programs and stories from newspapers, television, magazines and radio. Nontraditional and alternative campaign information mechanisms like radio talk shows and more feature-oriented TV interview shows also became highly visible and popular. ${ }^{10}$ Traditional news sources like the New York Times, news magazines

One 16-year study concludes that the long-term decline in national turnout was linked both to the drop in the percentage of voters who say they read newspapers on a regular basis and to decline in partisan identification over the period.

and network newscasts found themselves competing for stories and audiences with these alternative sources, which ranged from MTV and the Nashville Network to talk shows hosted by Larry King on television and Rush Limbaugh on radio. These expanded sources of campaign information coincided with the largest turnout in a presidential election since 1968. ${ }^{11}$

This study, based on this expanded media and political landscape in 1992, focuses on the relationship between a voters' information sources and whether they cast a ballot. Were voters who relied on one news medium more likely to cast a ballot than those who did not? In the super-charged news media environment of 1992, which information sources - if any - were significantly related to an audience member casting a ballot? And as candidates and voters prepare for Election Day 1996, are there lessons to be learned?

\section{Related studies}

Some small-scale studies have attempted to correlate news media usage of individual citizens and their voting patterns. Single-state studies that focus on where local voters said they received their information on public issues or election campaigns have found newspapers are the pre-eminent source of information for citizens most likely to vote. ${ }^{12}$

Studies of media use in the 1992 campaign produced varying results. David Weaver and Dan Drew ${ }^{13}$ examined campaign issue knowledge, predictors of campaign interest, and factors associated with likelihood of voting for a group of Indiana voters. Focusing primarily on alternative news sources, they found that exposure and attention to alternative media sources did not affect the likelihood of voting. In contrast, John Bare ${ }^{14}$ found a link among North Carolina voters between attention paid to television talk shows and stated intention to vote. Steve Chaffee, Xinshu Zhao and Glenn Leshner ${ }^{15}$, relying on surveys from 
Simon: Media use - $\mathbf{2 7}$

California and North Carolina, found that attention to newspaper coverage in 1992 was the best predictor of a citizen's knowledge about where a party stood on the issues, while television coverage was a better predictor of knowledge about where candidates stood on the issues. A related study ${ }^{16}$ found issueoriented voters used multiple media sources for information if they perceived an election contest to be close.

Longitudinal studies of presidential elections have produced similar findings. One 16-year study concludes that the long-term decline in national turnout was linked both to the drop in the percentage of voters who say they read newspapers on a regular basis and to decline in partisan identification over the period. ${ }^{17}$ One of the most comprehensive studies in this area focuses on the 10-percentage point drop in presidential election turnout between 1960 and 1980, as reported in the National Election Studies. ${ }^{18}$ It found that the decrease in active newspaper readership explained 33.5 percent of the turnout decline in the final four elections of the period, well beyond the impact of factors such as changes in age, partisanship, marital status, residential mobility, race, religion, sex and political efficacy. The author, Ruy Teixeira, concludes that "the decline in newspaper reading is the crucial development during this period."19

The present study uses the 1992 NES database to examine the relationship between turnout and the use of four sources of campaign information: newspapers, television, magazines and radio. This study is conceived around a single research question: did a voter's use of newspapers, television, radio or magazines as a source of campaign information in 1992 significantly explain whether they cast a ballot in the election, holding demographic and attitudinal characteristics constant? In other words, if one knew that a voter used a particular medium to obtain information on the campaign, could one tell whether that voter was more likely to have cast a ballot?

This approach allows the examination of the relationship between a voters' use of each individual information source and whether they voted. It also allows the assessment of the overall impact of a medium like television or radio, including alternative and traditional stories and programs. To focus solely on the alternative sources would be to ignore the traditional campaign information outlets that continued to inform millions of voters in 1992.

\section{Method}

The data in this study are part of the ongoing National Election Study surveys that are conducted by the Inter-university Consortium for Political and Social Research. ${ }^{20}$ The 1992 survey was based on responses from 2,485 adults both registered and non-registered voters - who were interviewed in a nineweek period prior to the November 3, 1992 presidential election. Most respondents were then reinterviewed between November 4, 1992 and January 13, 1993. This study is based on the 2,251 respondents who were successfully interviewed 
twice and also gave an answer when asked whether they had voted in the 1992 election. The potential sampling error, based on the proportion giving a dichotomous response estimated at .50 and calculated at a 95 percent reliability level, is $+/-1.96$ percent.

The study focuses on the dependent variable of whether respondents reported that they did or did not vote in November 1992. This was operationalized by using the question, "In talking to people about elections, we often find that a lot of people were not able to vote because they weren't registered, they were sick, or they just didn't have time. How about you - did you vote in the elections this November?" Seventy-seven percent of the respondents said they did vote; actual turnout in 1992 was 75.9 percent of registered voters and 55.2 percent of the voting age population. ${ }^{21}$ Unlike the 1988 NES survey, the 1992 NES survey did not independently check with local voter registration officials to validate whether respondents did or did not cast a ballot on Election Day.

This study analyzed turnout patterns, holding constant a variety of standard independent variables drawn from the voting literature, including demographics (age, marital status, education, income, gender, religion, race), political variables (political interest, political ideology, party affiliation, level of partisanship, level of political participation, level of political efficacy) and level of interpersonal communication about the campaign events.

Each media variable represented an index that measured two dimensions: exposure to the medium (whether a person had received any campaign information from the medium) and intensity of use (how much attention the person paid to campaign stories in that medium). The study combined the two dimensions into a single index because of the limitations posed by use of only exposure levels (which fail to measure intensity) or only intensity (which fails to measure level of exposure). ${ }^{22}$

In the analysis, a baseline correlation between each news medium and turnout was first computed. In the second phase of analysis, a three-step hierarchical regression was used to examine the relationship of the independent variables to turnout. Logit, a maximum likelihood estimator, was used due to its efficiency in analyzing binary dependent variables. ${ }^{23}$ Regression 1 estimates the role of only the demographic variables in explaining the variance in voter turnout. Regression 2 calculates the impact of the political variables by adding them to the model. Regression 3 adds the four media variables to see if they were significantly related to turnout and to see if they added to the ability of the model to predict turnout.

While this study examined the news media use by voters during the 1992 presidential campaign, the content of the actual mediated information was not examined. The content of differing stories in a single medium like newspapers, rather than the nature of the medium itself, could be an intervening variable..$^{24}$ This study also does not analyze the combined use of multiple news media by a respondent. 
Table 1: Hierarchical models of variables related to voter turnout (logit coefficients)

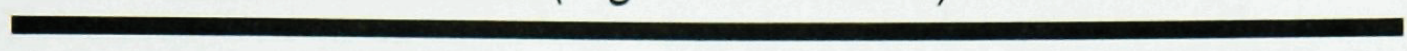

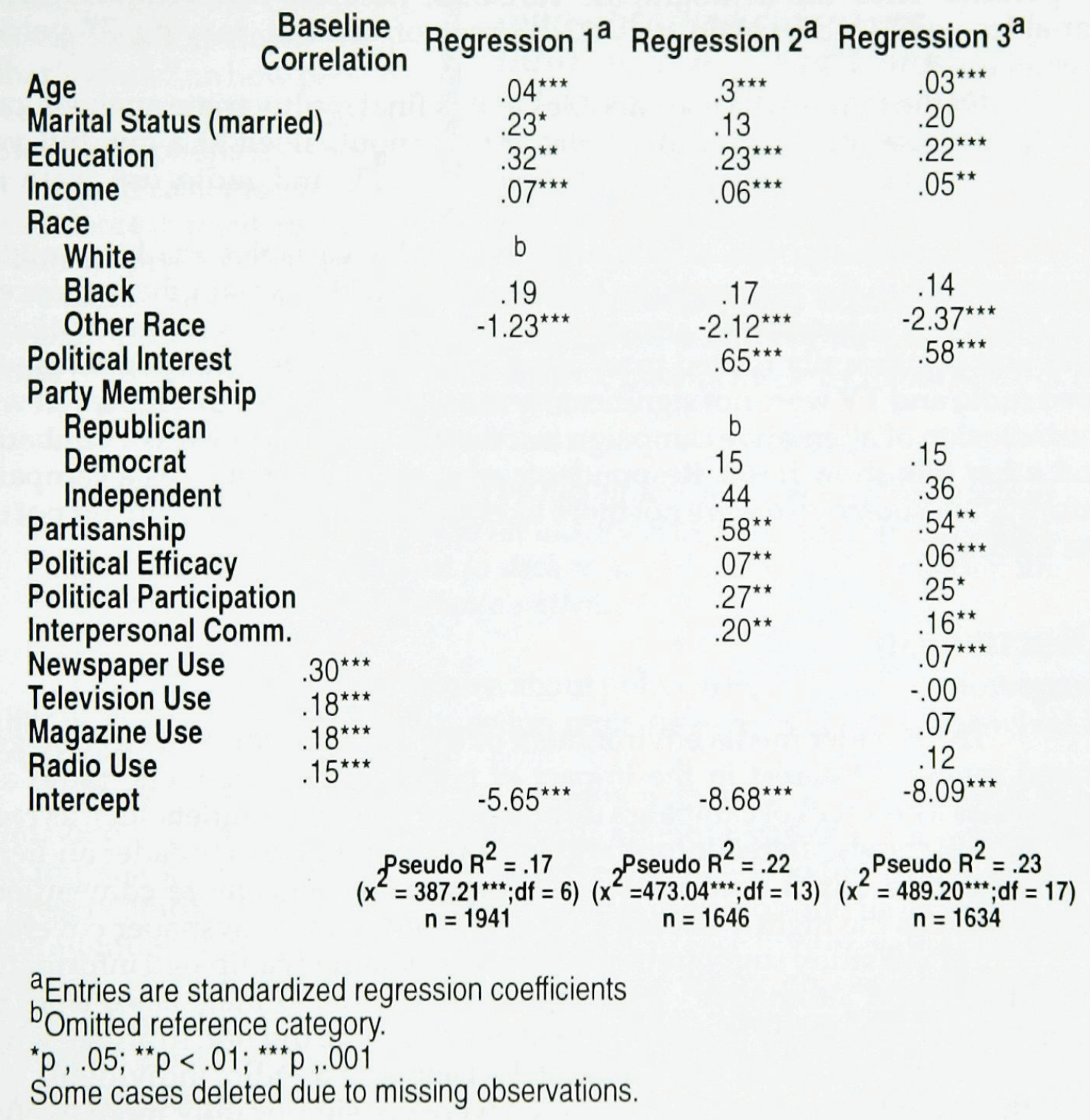

\section{Findings}

Use of four of the news media was significantly related to turnout in the initial baseline correlations. (see Table 1) Newspaper use for campaign information had the strongest association with turnout $(r=.30)$, followed by television and magazines $(r=.18$, respectively), and then radio $(r=.15)$. 
The first regression block, focusing only on non-political and nonmedia variables, showed such variables accounted for 17 percent of the variance in turnout among voters in 1992. The second block added political variables and increased the predictive value (pseudo $\mathrm{R}^{2}$ ) to 22 percent. The third block added the four media variables, which produced a modest increase in the pseudo $R^{2}$ to 23 percent. Thus the demographic variables, political variables and media variables combined explain only 23 percent of turnout, leaving 77 percent unexplained.

Of the four media use variables in this final multivariate analysis, only newspaper use was significantly related to turnout, albeit at a low but very significant level $(\mathrm{r}=.07, \mathrm{p}<.001)$. Magazine, TV and radio use were not significantly related to turnout.

In summary, the addition of the media variables made a modest improvement in the power of the regression model to explain the variance in turnout. Only respondents' use of newspapers for campaign information in 1992 was significantly related to whether or not they voted. Respondents who used radio and TV were not significantly more likely to vote in 1992, even with the inclusion of alternative campaign information sources like Rush Limbaugh and other talk show hosts. Respondents who used magazines as a campaign information source also were not more likely to vote than those who did not use the medium.

\section{Discussion}

The broader media environment of the 1992 presidential election generated renewed interest in the impact of television, newspapers, radio and magazines as sources of campaign information. New News outlets such as radio and TV talk shows offered information on the campaign to a broader audience who otherwise might not follow the campaign through more conventional means such as the nightly network TV news shows and newspaper coverage.

Yet this study suggests that voters who obtained campaign information - traditional and alternative - from television, radio and magazines were not significantly more likely to cast a ballot than those who did not. In an age where virtually every American home has a television and a radio, individuals who used those media to follow the campaign were not significantly more likely to take part in the election. Only adults who said they followed the campaign through newspapers were found to be more likely to vote.

The relationship between newspapers and turnout is consistent with past studies showing newspaper coverage is more likely to influence cognitive thinking than other media, ${ }^{25}$ increase political knowledge ${ }^{26}$ and help citizens discriminate among issues. ${ }^{27}$ This study also is consistent with the central findings of Steven Shaeffer and Teixeira, ${ }^{28}$ who examined changes in the presidential electorate over multiple elections and found that reduced newspa- 
Simon: Media use - 31

per use by voters accounted for a high percentage of the decrease in turnout in presidential elections over the past 30 years.

While this study explores the relationship between newspaper use and voting, the reason for the apparent connection is not immediately apparent. One possible explanation flows from Graber's work ${ }^{29}$ on how people process news. Graber found printed descriptions and analyses are much easier to process, contain more explicit information and are presented in a way Yet this study suggests that voters who obtained campaign information - traditional and alternative - from television, radio and magazines were not significantly more likely to cast a ballot than those who did not.

that readers could incorporate it with information they already possessed. Television stories provide less information in the audio portion and seemingly too much visual information for the audience member to fully make sense of it. In 1984, Graber wrote:

The interesting question raised by this situation concerns future political learning. What will happen to the quality of learning about public affairs if newspaper use continues to decline and electronic media capture an increasing share of the audience's attention? ${ }^{30}$

Given the continuing concern about political learning and civic responsibility in the United States, her question remains as relevant today as when it was first asked a dozen years ago.

The results of this study are at odds with Weaver and Drew, ${ }^{31}$ who found none of the media exposure and media attention variables they examined in an Indiana sample contributed to an increased likelihood to vote in 1992. In the present study, the use of a combined media indicator (media exposure and media attention) rather than separate measures for each may explain some of the difference. Weaver and Drew also based their study on respondents' preelection intention to vote, rather than asking them whether they had actually cast a ballot, and on a single-state Indiana sample instead of the national sample used in the present study.

Due to the study design, the specific contribution of the New News radio and TV formats to turnout in 1992 remains unclear. However, radio and TV as a whole did not appear to influence voter turnout, despite the large numbers of citizens who listened to and watched these accessible programs. Further research could establish whether the role of the radio and TV talk shows in 1996 and beyond is simply to turn politics into entertainment, rather than serving as an information source that could spur participation on Election Day.

This study makes no claim that newspaper use is the primary determinant of turnout or that it ranks in importance with such predictors as education 
and political interest. But this study demonstrates the value of using media variables to ${ }^{\mathrm{i}} \mathrm{mprove}$ the predictive power of turnout models. It also identifies newspaper use as the only significant media factor, of the four studied, in explaining whether an individual voted in the 1992 campaign.

The findings of this study come against a backdrop of nearly 200 daily newspapers ceasing publication since $1972,{ }^{32}$ a steady decrease in readership as a percentage of population, ${ }^{33}$ and a 30 -year trend toward increased reliance on television as a primary news source.34 In response, many newspapers continue to emulate the

Further research could establish whether the role of the radio and TV talk shows in 1996 and beyond is simply to turn politics into entertainment, rather than serving as an information source that could spur participation on Election Day.

format of USA Today, which imitates television coverage with colorful layouts and short stories and sacrifices many of the elements - longer stories, intense political coverage - that may contribute to the link between newspaper reading and higher turnout levels. Gannett's News 2000 guidebook for the chain's newspapers specifically recommends reducing coverage that is institutionally driven, such as political stories on City Hall, and replacing them by items that spur community interest such as covering shopping trends and sales. ${ }^{35}$

These newspaper changes, necessary as they may be for the industry's financial survival, are continuing as the 1996 election approaches. However, they may be undermining the advantages the medium has in presenting comprehensive information that can spur citizens to go to the polls on Election Day.

\section{Notes}

1. Paul Lazarsfeld, Bernard Berelson and Hazel Gaudet, The People's Choice: How the Voter Makes Up His Mind in a Presidential Campaign. New York: Columbia University Press, 1944.

2. Joseph T. Klapper, The Effects of Mass Communication. New York: Free Press, 1960.

3. Steven H. Chaffee, Xinshu Zhao and Glenn Leshner, Political knowledge and the campaign media of 1992. Communication Research, 21, 1994, pp. 305-325. Thomas E. Patterson, The Mass Media Election: How Americans Choose Their President. New York: Praeger, 1980.

4. Hyeon C. Choi and Samuel L. Becker, Media Use, Issue/Image Discriminations, and Voting. Communication Research, 14, 1987, pp. 267-290. Joseph Wagner, Media Do Make a Difference: The Differential Impact of Mass Media in the 1976 Presidential Race. American Journal of Politics, 27, 1983, pp. 407-430. 
Simon: Media use -33

5. David H. Weaver and Judith M. Buddenbaum, Newspapers and Television: A Review of Research on Uses and Effects. In G. Cleveland Wilhoit \& Harold de Bock (eds.), Mass Communication Review Yearbook 1 (pp. 371-381). Beverly, Hills, California: Sage, 1980.

6. Peter Clarke and Eric Fredin, Newspapers, Television and Political Reasoning. Public Opinion Quarterly, 1978, pp. 143-160.

7. Thomas Volgy and John E. Schwarz, On Television Viewing and Citizens' Political Attitudes, Activity and Knowledge: Another Look at the Impact of Media on Politics. Western Political Quarterly, 33, 1980, pp. 153-166.

8. Lee Becker and D. Charles Whitney, Effects of Media Dependencies: Audience Assessment of Government. Communication Research, 7, 1980, pp. 95-120.

9. Scott Keeter, The Illusion of Intimacy: Television and the Role of Candidate Personal Qualities in Voter Choice. Public Opinion Quarterly, 51, 1987, pp. 344-358. Doris Graber, Press and TV as Opinion Resources in Presidential Campaigns. Public Opinion Quarterly, 40, 1976, pp. 285-303.

10. Edwin Diamond, Martha McKay and Robert Silverman, Pop Goes Politics: New Media, Interactive Formats, and the 1992 Presidential Campaign. American Behavioral Scientist, 37, 1993, pp. 257-261. Mark Jurkowitz, Direct Access: The Old Rules Change in the Year of the New News. Boston Phoenix, December 25, 1992, pp. 6-8. Jon Katz, The Plugged-In Voter: The New News Has Reconnected People and Politics. Rolling Stone, 45-46, December 20-Jannary 2, 1992, pp. 115-118.

11. Royce Crocker, Voter Registration and Turnout: 1948-1992 (Publication 4-2 GOV). Washington, D.C.: Congressional Research Service, The Library of Congress, 1994.

12. Margaret K. Latimer and Patrick R. Cotter, Effects of News Measure on Selection of State Government News Sources (revisited). Journalism Quarterly, 62, 1985, pp. 3136. Joey Reagan and Richard V. Ducey, Effects of News Measure on Selection of State Government News Sources. Journalism Quarterly, 60, 1983, pp. 211-217. James Simon and Bruce D. Merrill, Revisiting Media Choice and Election Turnout. Southwestern Mass Communication Journal, 9, 1993, pp. 106-115.

13. David H. Weaver and Dan Drew, Voter Learning in the 1992 Presidential Election: Did the 'Nontraditional' Media and Debates Matter? Journalism Quarterly, 72, 1995, pp. 717.

14. John Bare, The Role of Non-Traditional News Sources in the 1992 Presidential Campaign. Paper delivered at the American Association for Public Opinion Research annual meeting, St. Charles, Illinois, 1993.

15. Chaffee, Zhao and Leshner, op. cit., pp. 305-325.

16. Nancy B. Lowden, Peter A. Anderson, David M. Dozier and Martha M. Lauzen, Media Use in the Primary Election: A Secondary Medium Model. Communication Research, 21, 1994, pp. 293-304.

17. Stephen D. Shaffer, A Multivariate Explanation of Decreasing Turnout in Presidential Elections, 1960-1976. American Journal of Political Science, 25, 1981, pp. 68-95.

18. Ruy A. Teixeira, Why Americans Don't Vote. New York: Greenwood, 1987.

19. Ibid., p. 88

20. Warren E. Miller, Donald R. Kinder and Steven J. Rosenstone, American National Election Study 1992: Pre- and Post-Election Survey. Ann Arbor, Michigan: InterUniversity Consortium for Political and Social Research, 1993.

21. Pamela J. Shoemaker and Stephen D. Reese, Exposure To What? Integrating Media 
Content and Effects Studies. Journalism Quarterly, 67, 1990, pp. 649-652.

22. Crocker, op. cit., 1994.

23. John H. Aldrich and Forrest D. Nelson, Linear Probability, Logit and Probit Models. Newbury Park, California, Sage, 1984.

24. Jack McLeod and Daniel G. McDonald, Beyond Simple Exposure: Media Orientations and Their Impact on Political Processes. Communication Research, 12, 1985, pp. 333.

25. Weaver and Drew, op. cit., 1995, pp. 7-17.

26. Chaffee, Zhao and Leshner, op. cit., 1994, pp. 305-325.

27. Choi and Becker, op. cit., 1987, pp. 267-290.

28. Shaffer, op. cit., 1981, pp. 68-95. Teixeira, op. cit., 1987. Ruy A. Teixeira, The Disappearing American Voter. Washington, D.C.: Brookings, 1992.

29. Doris Graber, Processing the News: How People Tame the Information Tide. New York: Longman, 1984.

30. Ibid., p. 214.

31. Weaver and Drew, op. cit., 1995, pp. 7-17.

32. Editor and Publisher International Yearbook 1993. New York: Editor and Publisher, 1993.

33. Harold Stanley and Richard G. Niemi, Vital Statistics on American Politics (2nd ed.). Washington, D.C.: Congressional Quarterly Press, 1990.

34. America's Watching: Public Attitudes Toward Television 1992. New York: National Television Association and the National Association of Broadcasters, 1992. 35. Patrick M. Reilly, Gannett Tests Formula to Lure Readers. Wall Street Journal, December 6, 1991, pp. B1, B5. 
Copyright of Newspaper Research Journal is the property of Newspaper Research Journal. The copyright in an individual article may be maintained by the author in certain cases. Content may not be copied or emailed to multiple sites or posted to a listserv without the copyright holder's express written permission. However, users may print, download, or email articles for individual use. 